CLINICAL LINGUISTICS \& PHONETICS, 1997, vol. 11, NO. 4, 319-338

\title{
Long-distance place assimilation with an interacting error pattern in phonological acquisition
}

\author{
D. A. DINNSEN, J. A. BARLOW \\ and M. L. MORRISETTE \\ Indiana University, Bloomington, IN, USA
}

(Received 7 February 1996; accepted 7 May 1996)

\begin{abstract}
Two commonly occurring and independent error patterns in children's early speech are examined to determine how and to what extent they might interact. One error pattern replaces velar consonants with coronals, and the other replaces a coronal with a consonant that agrees in place of articulation with some other consonant elsewhere in the word. A range of interactions is observed within and across children with regard to whether the product of one error pattern can serve as the target of the other. The different interactions motivate different claims about the nature and substance of children's underlying representations, which in some cases may differ from those of the ambient system. An extension to underspecification theory is advanced which allows underlying representations to be radically underspecified and in certain cases also to be specified for a default feature.
\end{abstract}

Keywords: place assimilation, acquisition, phonology, error patterns.

\section{Introduction}

In the course of phonological acquisition (normal and disordered), children's substitution errors often merge phonemic contrasts of the ambient system. Two presumably independent but potentially interacting types of error patterns have been observed. One type results in the simple substitution of an unmarked sound for a more marked sound. A typical example would include the replacement of stops for fricatives (stopping), of glides for liquids (gliding), or of coronals for velars (fronting) (e.g. Dyson, 1986; Ingram, 1989). In any one of these cases, then, the child's error pattern would fail to distinguish between a marked and unmarked sound of the ambient system, possibly in all contexts, resulting in a superficial merger. The other type of error pattern is assimilatory in nature, resulting in the substitution of a marked sound for a less marked sound, but only in the context of another marked sound. A standard example of this is long-distance place assimilation, where an unmarked coronal consonant is replaced by a more marked labial or velar as a result of

Address correspondence to: Daniel A. Dinnsen, Department of Linguistics, Indiana University, Memorial Hall 332, Bloomington, IN 47405, USA. 
assimilation with a segment elsewhere in the word (e.g. Chin, 1993; Cruttenden, 1978; Donahue, 1986; Ferguson, Peizer and Weeks, 1973; Menn, 1971; Smith, 1973; Stoel-Gammon and Stemberger, 1994). Thus, the word 'Tom' might be realized as [pam] by regressive place assimilation, and the word 'boat' might be realized as [bop] by progressive assimilation.

There is a potential for an interaction between these two types of error patterns when a process of the first type yields an unmarked segment that is a possible target of an assimilatory process of the second type. A particular instantiation of this would obtain if one error pattern replaced all velars with coronals and the other error pattern replaced coronals with labials when a labial occurred elsewhere in the word. The general issue is whether the product of one error pattern can be the target of another. Put in terms of these specific error patterns, do coronals resulting from fronting act as other coronals do with respect to long-distance place assimilation?

The purpose of this paper is two-fold: (a) to document how these two types of error patterns interact in different children's sound systems, and (b) to consider the implications of such interactions for claims about children's underlying representations. Interacting error patterns are important to the issue of how children represent words underlyingly, especially in light of proposals regarding the (under)specification of phonological representations. Underspecification theory makes substantive claims about which features of a sound are specified underlyingly. All non-contrastive features are presumed to be underspecified, and within the particular framework of radical underspecification theory (e.g. Archangeli, 1988), even some contrastive features (usually the unmarked member of a contrast) are also underspecified. One claim of such a theory is that assimilations would typically derive from a process that spreads a specified feature to a target that is underlyingly underspecified for such a feature. The difference between specified and underspecified features results in certain predicted asymmetries in terms of which sounds can serve as potential triggers/blockers and targets of assimilation. Because underspecified features are not available to be spread, they cannot trigger or block assimilation. The underspecification of a feature does, however, render a segment vulnerable as a potential target of spreading. The presence of a specified feature makes it a possible trigger or blocker for spreading but an unlikely target. To illustrate the predicted asymmetries, consider the schematization in Figure 1. In Figure 1a, a specified feature $[+F]$ (the trigger) is available to be spread leftward to a segment which is underspecified for a feature on the same tier (the target). As a result of the spreading, two different segments share a feature to yield the effect of assimilation. In Figure 1b, however, the spreading of a specified feature is blocked for lack of an underspecified target. Each segment is specified for a different feature on the same tier.

By extending underspecification theory to an account of children's substitution errors (both assimilatory and non-assimilatory), some claims can be made about how children represent and specify their sounds underlyingly. For example, those segments which are targets of assimilation would presumably be underspecified underlyingly for the assimilating feature. On the other hand, those segments which block as targets of assimilation would have to be specified for the relevant feature. With regard to place features, the evidence from fully developed languages alone would suggest that coronals are underspecified for place with the feature [coronal] filled in by default (Paradis and Prunet, 1991). Coronals should thus be vulnerable to assimilatory place errors as a result of their being underspecified for place. The observed non-assimilatory substitution of coronals for velars would also suggest 


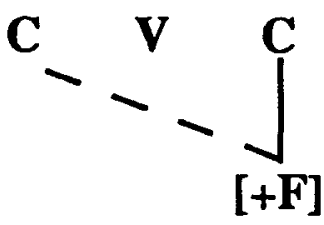

(a)

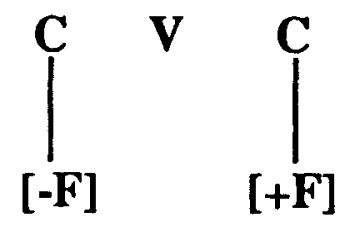

(b)

Figure 1. Trigger/target asymmetries in assimilation: (a) assimilation triggered by specified feature that can spread to underspecified target; (b) assimilation blocked if potential target is specified.

that [coronal] is the default place feature filled in by rule. That is, if a child does not distinguish between coronals and velars in his or her own production, there may be no need to distinguish them underlyingly, allowing them to be underspecified for place. If these undifferentiated and underspecified segments are moreover supplied with their place feature by default, an account is offered for the fact that the phonetic result is a coronal rather than some other place of articulation. Under such an account, non-assimilatory substitutions come about from a lack of differentiation at the underlying level of representation and not as a result of some feature-changing rule. On the other hand, assimilatory substitutions derive from a process that spreads a specified feature to an underspecified segment. In either case, the segment produced in error is underspecified underlyingly.

While it is an empirical issue whether substitution errors do in fact derive from an underspecified representation, crucial evidence about the nature of children's underlying representations is often difficult to come by. A long-standing and still unresolved issue in the characterization of developing systems has been whether or not children's underlying representations are ambient-like. The issue arises for at least two reasons. First, children's early speech production evidences a substantial reduction in the number or types of phonological contrasts compared to the ambient system, resulting (at least superficially) in a mismatch between the child's system and the ambient system. Second, it is widely held that many children 'know' more phonologically than their production facts might suggest. Their presumed perceptual abilities are most often cited in this regard and suggest a further mismatch systeminternally between perception and production. To accommodate both mismatches, some have suggested that children's underlying representations may be ambient-like (e.g. Smith, 1973). Under this view, perceptual abilities are taken to more accurately reflect the substance of the child's underlying representations, and the production facts derive from these representations by the application of rules of absolute neutralization. The general results from the abstractness controversy, however, call into question such abstract representations and rules (or their application), at least as regards fully developed systems (e.g. Kiparsky, 1976). Additionally, claims about 
children's perceptual abilities must be regarded with caution. For example, the fact that a child may comprehend and even reliably identify two different words when spoken by others at best establishes only that the child recognizes some difference between those two words, but not necessarily between any other words and not necessarily in terms of the intended difference within the ambient system. This point is further corroborated by those studies that have found that some children weight acoustic cues of the ambient system differently from adult listeners (e.g. Nittrouer and Studdert-Kennedy, 1987). Additionally, even if perception were better than production for some children or with regard to some words, perceptual deficits have been observed and thus fail to support ambient-like underlying representations for all children or for all words (e.g. Kronvall and Diehl, 1954). In general, it is acknowledged that the many methodological difficulties associated with perceptual studies of children between the ages of 2 and 10 have yielded precious little information about children's perceptual abilities (e.g. Barton, 1980). At the very least, then, claims about children's underlying representations based on such information entail questionable rule types and are not as well supported as we might like. An alternative approach to the issue of children's underlying representations has been to separate production from perception by postulating, for example, a dual representation or a 'two-lexicon model' of grammar, with one representation incorporating information relevant to perception and a different representation incorporating information relevant to production (e.g. Menn, 1976; Spencer, 1986). While such a model admittedly raises other concerns about potential duplication, and about how the two representations might be related, it does at least allow for the possibility that information is organized, represented, and processed differently for production and perception tasks. It also sanctions a focus on the nature of representations of either type independent of the other. The greater availability of interpretable and reliable production data in the published case studies offers some advantages to a production orientation. Accordingly, the focus of this study will be on production facts with an attempt to determine the nature of the underlying representations relevant to production. As will be seen, such representations may also be relevant to the presumed perceptual facts.

If the production facts reveal that coronals corresponding to velars can serve as targets of long-distance place assimilation, then it would appear that they must be underspecified underlyingly in the same way that the other coronals are. On the other hand, if the coronals corresponding to velars act differently from other coronals that do undergo assimilation, then there must be a place distinction specified underlyingly. The precise nature of that distinction is a central concern of this paper and will be argued to further motivate a proposed extension to underspecification theory which allows the default value of a feature to be both underspecified and specified.

This proposed extension was first put forward in Dinnsen (1993) as 'shadowspecification' to account for various other acquisition phenomena. ${ }^{1}$ Among those phenomena was the differential behaviour of phonetically merged segments. One example from that study found that while a child replaced fricatives with stops, only those intervocalic coronal stops corresponding to ambient stops could undergo a rule of glottal replacement. Coronal stops corresponding to fricatives could not

${ }^{1}$ Other phenomena in fully developed systems have motivated a similar proposal in terms of combinatorial specification within Grounded Phonology (Archangeli and Pulleyblank, 1994). 
undergo the rule. Consistent with the child's production facts, it was argued that this child had internalized two different kinds of stops. Some stops were underspecified for the default feature [-continuant], and other stops were (shadow-)specified for that same feature. That distinction alone was sufficient to trigger the rule's proper application to only some stops, and did not attribute to the child knowledge of fricatives, which never occurred in the child's own speech. The theoretical and descriptive value of shadow-specification is further evaluated here by considering potential interactions of error patterns, especially those involving place features and assimilation.

In the following three sections, three case studies from normally developing and phonologically disordered children are presented, each illustrating a different interaction of the same two error patterns. In each case an account is argued for which assumes that some of the child's underlying representations differed from those of the ambient system. The paper concludes with a consideration of the implications of these interacting error patterns for an alternative constraint-based theoretical framework and for their developmental and clinical relevance.

\section{Case study 1}

The two error patterns of interest were both evident in the speech of a phonologically disordered child, Subject 18 (age 4;3). This subject was selected from a larger archival study of children with functional (non-organic) speech disorders of a moderate to severe nature. Various aspects of the children's phonologies from that study have been described elsewhere (e.g. Dinnsen and Chin, 1994; Dinnsen, Chin, Elbert and Powell, 1990). The data in (1) exemplify the two error patterns and their interaction at a single point in time prior to any clinical treatment. In (1a), a process of longdistance progressive and regressive place assimilation is illustrated such that a coronal consonant was replaced by a labial when a labial consonant occurred elsewhere in the word. Forms such as those in (1b) show that coronal consonants were produced correctly in initial and final contexts when a labial consonant did not occur in the word, and labial consonants were realized appropriately as labials independent of context. These coronals thus exhibited the expected behaviour of underspecified segments. That is, they were targets (but not triggers) of place assimilation, and they were realized correctly as coronals when a triggering [labial] feature was not present. The forms in (1c), however, show that some coronals resisted place assimilation, even though a labial consonant occurred in the word. The assimilation-resistant coronals were themselves the product of another error pattern, fronting, and corresponded with velars in the ambient system. As the forms in (1d) illustrate, velars were generally realized incorrectly as coronals. The forms in (le) illustrate, however, that this fronting error pattern was not systematic; that is, some ambient velars did serve as targets of place assimilation. The relevance of this latter point will be considered in greater detail below.

(1) Place assimilation asymmetries (Subject 18, age 4;3)

(a) Progressive and regressive place assimilation

$\begin{array}{llll}\text { [perp] } & \text { 'paint' } & \text { [pæp] } & \text { 'pants' } \\ \text { [pup] } & \text { 'push' } & \text { [pupi] } & \text { 'pushing' } \\ \text { [berp] } & \text { 'bathes' } & \text { [bevp] } & \text { 'belt' } \\ \text { [bup] } & \text { 'boot' } & \text { [bupi] } & \text { 'bootie' }\end{array}$




$\begin{array}{llll}\text { [pup] } & \text { 'soup' } & \text { [pupi] } & \text { 'soupy' } \\ \text { [pop] } & \text { 'soap' } & \text { [popi] } & \text { 'soapy' } \\ \text { [bibws] 'zebra' } & \text { [pap] } & \text { 'sharp' } \\ \text { [prp] } & \text { 'chips' } & \text { [bıp] } & \text { 'jump' }\end{array}$

(b) Coronals and labials realized appropriately

$\begin{array}{llll}\text { [tit] } & \text { 'teeth' } & \text { [tero] } & \text { 'tail' } \\ \text { [dru] } & \text { 'deer' } & \text { [dit] } & \text { 'dish' } \\ {[\mathrm{it}]} & \text { 'eat' } & \text { [hæt] } & \text { 'hat' } \\ \text { [pI }] & \text { 'pig' } & \text { [par] } & \text { 'pie' } \\ \text { [pwer] } & \text { 'play' } & {[\mathrm{br}]} & \text { 'big' } \\ {[\mathrm{b} \Lambda]} & \text { 'buzz' } & \text { [bwo] } & \text { 'blow' }\end{array}$

(c) Assimilation blocked when coronal corresponded with velar [bædi] 'baggie' [prdi] 'piggie'

(d) Ambient velars realized as coronals

$\begin{array}{llll}\text { [tæt] } & \text { 'cats' } & \text { [teIt] } & \text { 'cakes' } \\ \text { [d } \Lambda \text { di] } & \text { 'ducky' } & \text { [wat] } & \text { 'rock' } \\ \text { [deIt] } & \text { 'gate' } & \text { [dot] } & \text { 'goat' } \\ \text { [dadi] } & \text { 'doggie' } & \text { [Idi] } & \text { 'Ziggy' }\end{array}$

(e) Some ambient velars targeted for assimilation

\begin{tabular}{|c|c|c|c|}
\hline [bæp] & 'back' & [biop] & 'milk' \\
\hline [bup] & 'book' & [bupi] & 'book' (dim.) \\
\hline [pæp] & 'cabs' & [bip] & 'gift' \\
\hline$[p \wedge p]$ & 'cup' & {$[\mathrm{p} \wedge \mathrm{pi}]$} & 'cup' (dim.) \\
\hline
\end{tabular}

These various effects do not appear to be attributable to the quality of an adjacent vowel. Note especially that both rounded and unrounded vowels occurred in cases of place assimilation, and rounded and unrounded vowels occurred in cases of fronting. The fact that some coronals were targets of assimilation, and others were not, suggests that these coronals were differentiated somehow underlyingly. At least two possible accounts present themselves. First, since the assimilation-resistant coronals corresponded with ambient velars, and since the targets of assimilation generally corresponded with ambient coronals, it might be tempting to account for this differential behaviour among coronals by postulating ambient-like underlying representations along with two extrinsically ordered rules. Specifically, the assimilation-resistant coronals (1c) would be postulated to be velars underlyingly with a specified [dorsal] feature, and the targets of assimilation would be postulated to be coronals that are underspecified for place. An underlying distinction would thus obtain between underspecified coronals and specified velars, and this distinction would be sufficient to allow the coronals (but not the velars) to uniquely undergo the assimilation rule, i.e. to be targets of place assimilation. A subsequent rule (fronting) would somehow then have to change velars into coronals after the place assimilation rule has had an opportunity to apply in a counterfeeding interaction. It is not crucial to the argument whether the fronting substitution comes about from a process that delinks the [dorsal] feature allowing [coronal] to be filled in by default, or alternatively from some feature-changing rule. Sample derivations of forms in (1a) and (1c) are given in (2). Place assimilation is able to apply to the 
coronal in $(2 \mathrm{a})$, but fronting is inapplicable. In (2b), the structural description of place assimilation is not satisfied at that point in the derivation, blocking its application. Fronting then applies, yielding a coronal.

(2) Place assimilation ordered before fronting.

(a) Sample derivation of forms in (1a)

/but + i/ 'bootie'

bupi place assimilation

- fronting

[bupi]

(b) Sample derivation of forms in (1c)

$\begin{array}{ll}\text { /pIg }+\mathrm{i} / & \begin{array}{l}\text { 'piggie' } \\ \text { place assimilation }\end{array} \\ \text { pIdi } & \text { fronting } \\ \text { [pIdi] } & \end{array}$

There are several problems with this account. First, while the differential behaviour of coronals suggests that the child internalized some difference between coronals and velars of the ambient system, it says nothing necessarily about what that difference might be in the child's system. This, and the absence of a phonemic contrast in any context between coronals and velars in the child's system, fail to provide any evidence that the child represented these coronals specifically as velars. The postulation of underlying segment types that never occur phonetically would thus be highly abstract. Additionally, as noted above, the substitution pattern for velars was not systematic, with some ambient velars (1c) resisting assimilation and other velars (1e) showing effects of having undergone the assimilation. Since the operation of the assimilation rule was presumably limited to coronals, there would appear to be two possibilities for those words in (1e). If the velars in those words were indeed represented as velars underlyingly, then the putative fronting rule would have needed to be ordered to apply before the assimilation rule in a feeding relation as shown in (3). This, however, entails just the opposite rule ordering required for the other forms, resulting in an ordering paradox.

(3) Fronting ordered before place assimilation

/buk $+\mathrm{i} /$ 'book' (dim.)

buti fronting

bupi place assimilation

[bupi]

The only real alternative to the ordering paradox is to assume that the ambient velars of those words in (1e) were represented incorrectly as coronals underlyingly. Thus, while the data in (1) motivate an underlying distinction, they do not motivate specifically the ambient place distinction, nor do they motivate the distinction for all the same words. The problem then is to arrive at an account that will distinguish the assimilation resistant coronals in (1c) from those segments that undergo assimilation in (1a) and (1e) and to do so in a way that does not attribute to the child knowledge of contrasts that never appeared in the child's speech.

The solution to this problem is sketched in Figure 2. First, in Figure 2a, the 


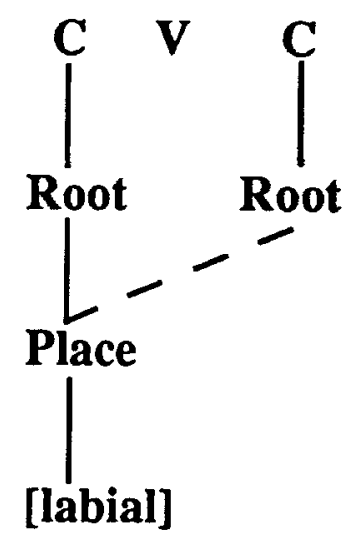

(a)

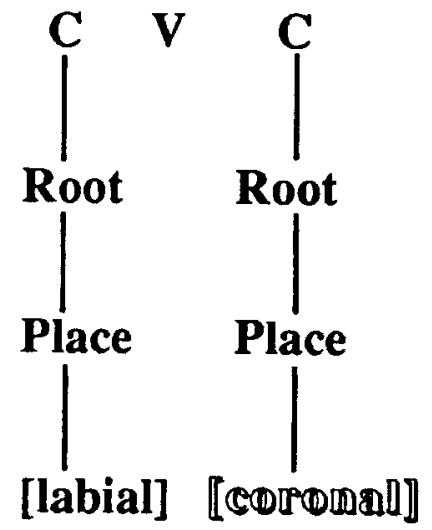

(b)

Figure 2. Geometric account of place asymmetries: (a) specified labial spreads to underspecified coronal; ( $b$ ) spreading blocked by shadow-specified coronal.

segments that were targets of place assimilation (1a) and (1e) can be assumed to be underspecified for place underlyingly. These underspecified segments then qualify as possible targets for the spreading of a place node from a segment specified as [labial]. The different behaviour of the assimilation-resistant coronals (1c) requires an underlying distinction that is capable of blocking place spreading in these words. If these coronals were assumed to be specified in some way for place, spreading would be blocked on principled grounds for lack of a target. The real issue then becomes what the specified place feature is. There are, of course, many possible diacritic feature markings that might be used, but all are arbitrary. If, on the other hand, the distinguishing feature were restricted to a phonetically interpretable place feature that is also consistent with the child's production facts, then the minimally necessary non-arbitrary place specification would have to be the feature [coronal]. This, however, would entail the specification and underspecification of the same feature in the same child's system. General underspecification theory does not allow such an option, but the proposed extension, namely 'shadow-specification' (Dinnsen, 1993), would yield precisely the desired effect. In this extended framework, it is only 
a default feature that can be both specified and underspecified. A phonological distinction is thereby achieved between two segments without necessarily introducing a phonetic distinction. For example, then, with regard to the default place feature [coronal], the phonological difference between an underspecified coronal and a shadow-specified coronal would be sufficient to render two segments distinct for purposes of a phonological rule such as long-distance place assimilation. The coronals in (1c) would thus be assumed to be shadow-specified as [coronal], as shown in Figure 2b. These shadow-specified coronals would block as a target of assimilation while allowing the underspecified coronals to undergo the rule. In words where the triggering labial consonant was not present, (1b) and (1d), the phonological distinction between a shadow-specified and underspecified coronal would be merged phonetically as a result of [coronal] being supplied by default to the underspecified segments of ( $\mathrm{lb}$ ). By this account there is no 'process' of fronting in the conventional sense. Ambient velars such as those in (1d) would instead be internalized incorrectly by the child as coronals, but coronals that are distinct from ambient underspecified coronals (1b).

The case presented here further supports and elucidates shadow-specification in several critical respects. First, shadow-specification was originally motivated based on the differential behaviour of phonetically identical segments with regard to nonassimilatory phenomena. The range of phenomena exhibiting differential behaviour of segments is now being extended to include assimilatory phenomena. Second, earlier work has had to assume somewhat arbitrarily which of the two phonetically identical segments is shadow-specified and which is underspecified. The observed asymmetries associated with what can block or be a target of assimilation do, however, provide empirical evidence for the choice. In this particular case it was the ambient coronals that were underspecified for place, given that they served as targets of assimilation. Those coronals that happened to correspond with ambient velars and more importantly blocked assimilation must have been shadow-specified as [coronal]. Even more importantly, however, not all ambient velars acted the same, and thus not all were shadow-specified. Some ambient velars (1e) acted as ambient coronals (1a) in terms of assimilation and must therefore have been represented in the same way, that is, as underspecified. This account entails the claim that the ambient velars in (1c-e) were represented incorrectly (relative to the ambient system) by the child at the underlying level. As discussed above, any account must make this assumption about at least the forms in (le). While the underspecified representations for (1e) can be considered different or incorrect relative to the ambient system, they did not contradict any properties of that system. That is, all of their underlyingly specified features were a subset of the features for both coronals and velars. The forms in (1c) and (1d) were incorrect in a different sense. That is, while the specification of [coronal] for these forms was in conflict with the ambient [dorsal] place feature, this at least approached correctness in that it yielded a representation that was distinct from those in (1a). That specification was moreover compatible with the child's production facts.

These different degrees of incorrectness among the underlying representations may have been a consequence of how this child's place contrasts evolved. That is, at an earlier stage of development, this child might not have distinguished ambient coronals and velars in any way, having underspecified both. The forms in (1e) might have been remnants of that earlier stage. The shadow-specification of those forms in (1c) and (1d) might thus have represented the first phase of acquiring the ambient 
contrast, even if it was not phonetically implemented as in the ambient system. Whatever the actual course of development, the contrast must have diffused gradually through the lexicon in order to have resulted in the differential behaviour of ambient velars (1c) and (1e).

The particular interaction of the two error patterns in this case revealed that coronals were differentiated underlyingly and that it was the coronals corresponding to velars that could block assimilation. Shadow-specification was thus limited to segments that were the product of the fronting error pattern. The question can be raised whether these blocking effects (and thus shadow-specification) can also obtain in sounds that are produced correctly. In the following section these same two error patterns will be shown to have interacted in a way that required an underlying distinction, but where the product of one error pattern was the target of the other.

\section{Case study 2}

Fronting and long-distance place assimilation also co-occurred in the speech of another phonologically disordered child, Subject L.P. (age 3;5). ${ }^{2}$ This child was selected from a similar but independent archival study of children with functional speech disorders. Many of the children's phonologies from that study have been described elsewhere (e.g. Gierut, 1985, 1994; Gierut, Simmerman and Neumann, 1994). Velars were excluded from the inventory and were replaced by coronals, as shown in (4). This resulted in a superficial merger of a place contrast inasmuch as ambient coronals and velars were produced as coronals.

(4) Velars replaced by coronals (fronting) (Subject L.P., age 3;5)

$\begin{array}{llll}\text { [dou?] } & \text { 'coat' } & \text { [dert] } & \text { 'gate' } \\ \text { [dolo] } & \text { 'colour' } & \text { [dæ?] 'catch' } \\ \text { [dædr?] } & \text { 'cracker' } & \text { [darro] } & \text { 'tiger' }\end{array}$

While velars were generally replaced by coronals, they were also replaced by labials under other circumstances, i.e. only when a labial consonant occurred elsewhere in the word, suggestive of assimilation. The data in (5) illustrate some of the conditions on this child's process of long-distance place assimilation. In (5a), an ambient velar was replaced by a labial when a labial consonant preceded or followed. Velars were thus possible targets of assimilation in this case. The ambient coronals in $(5 \mathrm{~b})$, however, were realized with the appropriate coronal place of articulation even though a labial consonant occurred in the word. These coronals resisted assimilation. Finally, in (5c), we see that some ambient coronals were subject to assimilation.

(5) Place assimilation (Subject L.P., age 3;5)

(a) Velars replaced by labials when labial occurred elsewhere in the word

$\begin{array}{llll}\text { [bıbi] } & \text { 'gum' (dim.) } & \text { [b } \Delta \text { bi] } & \text { 'cup' (dim.) } \\ \text { [bæmbə] } & \text { 'camera' } & \text { [bubi] } & \text { 'book' (dim.) } \\ \text { [bæbi] } & \text { 'baggie' } & \text { [brbi] } & \text { 'piggie' }\end{array}$

\footnotetext{
${ }^{2}$ Because this child's data were from another database where he was coincidentally identified as Subject 18, this child is arbitrarily being identified as L.P.
} 
(b) Coronals blocked as targets of assimilation

$\begin{array}{llll}\text { [dombi] } & \text { 'Tommy' } & \text { [dibi] } & \text { 'zipping' } \\ \text { [dupi] } & \text { 'soupy' } & \text { [doubi] } & \text { 'soapy' } \\ \text { [bæn] } & \text { 'van' } & \text { [biæPnou] } & \text { 'piano' }\end{array}$

(c) Some ambient coronals targeted for assimilation

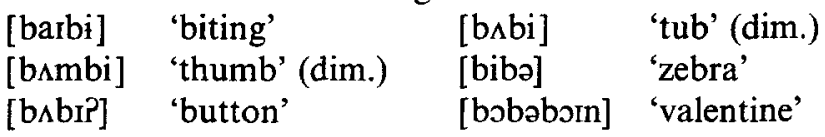

The two case studies presented here were similar in several respects, but they differed in terms of what the primary target of assimilation was. To account for the facts of this case, and how they differ from the prior case, two possibilities are considered. One possibility might be that the formulation of the place assimilation rule was different in the two cases. That is, in the case of Subject L.P., the assimilation rule would be stipulatively restricted to velar targets (and in the case of Subject 18 to coronal targets). This account encounters several difficulties. First, it would require the postulation of some velars underlyingly in at least (5a), despite the fact that velars never occurred phonetically in these or any other words. Also, in order for those ambient coronals in (5c) to be targets of assimilation, it would be necessary to postulate them as velars underlyingly. It is difficult to see what would have motivated this child to make such an assumption since these coronals were never realized as velars in the ambient system. Additionally, the nature of the assimilation rule would have to be different from other assimilations, i.e. feature-changing (or possibly spreading with subsequent delinking of the [dorsal] feature). Also, the specified nature of the target in this account would be in conflict with the underspecified targets of other assimilatory processes. Even if these difficulties were overlooked, this account cannot maintain ambient-like underlying representations for all words in this child's system.

Some of the assumptions of this faulty account are explicated in the sample derivations in (6). In (6a), place assimilation would apply to the underlying velar, changing it to a labial in accord with the following labial consonant. Fronting would be bled by the prior application of place assimilation. If fronting had applied first, it would have incorrectly bled place assimilation. In (6b), neither place assimilation nor fronting is applicable since there are no velars in the underlying representation of forms such as those in (5b). In (6c), an ambient coronal is postulated to be a velar underlyingly in order to be a target of place assimilation. Finally, in (6d), an underlying velar is postulated, but place assimilation cannot apply because a triggering labial consonant is not present. Fronting would then apply to convert the underlying velar to a phonetic coronal.

(6) Sample derivations

$\begin{array}{ll}\text { (a) } / \mathrm{k} \wedge \mathrm{p}+\mathrm{i} / & \text { 'cup' (dim.) } \\ \mathrm{b} \wedge \mathrm{bi} & \text { place assimilation } \\ & \text { fronting } \\ {[\mathrm{b} \wedge \mathrm{bi}]} & \end{array}$

\footnotetext{
${ }^{3}$ Voicing errors are irrelevant to the point at hand.
} 

(b) /soup +i/ 'soapy'
$[\text { doubi }]^{4}$
fronting
- place assimilation
(c) $/ \mathbf{k} \Lambda \mathrm{b}+\mathrm{i} / \mathrm{tub}$ ' (dim.)
b^bi place assimilation
- fronting
[bıbi]
$\begin{array}{ll}\text { (d) } / \text { gert/ } & \text { 'gate' } \\ -- & \text { place assimilation } \\ \text { dert } & \text { fronting } \\ \text { [dert] } & \end{array}$

An alternative account (sketched in Figure 3) is available which avoids the abstractness concerns noted above and is wholly consistent with the characterization of other assimilatory phenomena. First, since ambient velars served as targets of assimilation, they acted as if they were underspecified for place. If velars were assumed to be underspecified in this child's system, the feature [coronal] would be supplied by default, accounting for the error pattern in (4). Additionally, when these same underspecified segments occurred in words with a labial consonant (as in Figure 3a), the very same place assimilation rule found in Subject 18's system would spread the specified [labial] feature to the underspecified target, accounting for the forms in $(5 a)$. The coronals in $(5 b)$, which resisted assimilation, acted as blockers of assimilation, i.e. as if they were specified for place. Since these assimilation-resistant coronals appeared phonetically as coronals, a more concrete assumption (consistent with the child's production facts) would be that they were shadowspecified underlyingly for the default feature [coronal] (as in Figure 3b). An underlying distinction between underspecified and shadow-specified segments would thus be introduced, accounting for the differential behaviour in (5a) and (5b). For the most part this distinction coincided with the ambient distinction, although the substance of the distinction was different. The few cases where an ambient coronal did undergo place assimilation as in ( $5 \mathrm{c}$ ) would appear to include segments that were underspecified for place (as in Figure 3c). The claim would be that this child did not differentiate the ambient coronals of these words in (5c) from the ambient velars of the words in (5a). This certainly seems plausible if, at an earlier stage of development, ambient coronals and velars were not phonologically differentiated by this child. The forms in (5c) might then have been remnants of that earlier stage.

The account argued for in the case of Subject L.P. employed all the same principles and constructs required for Subject 18. That is, underlying representations were radically underspecified and shadow-specified for the place feature [coronal]. The same rule of long-distance place assimilation spread a specified [labial] feature to a target that was underspecified for place. The feature [coronal] was filled in by default. The only difference of concern was the class of segments that were shadowspecified. In the case of Subject 18, the shadow-specified segments (partially) corre${ }^{4}$ This child replaced many fricatives with stops, but this error pattern is not relevant to
the issue. 

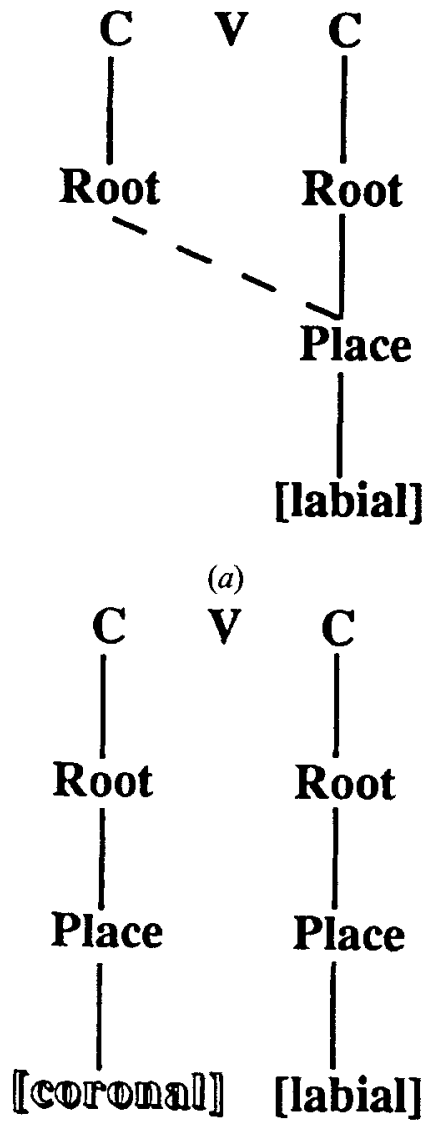

(b)

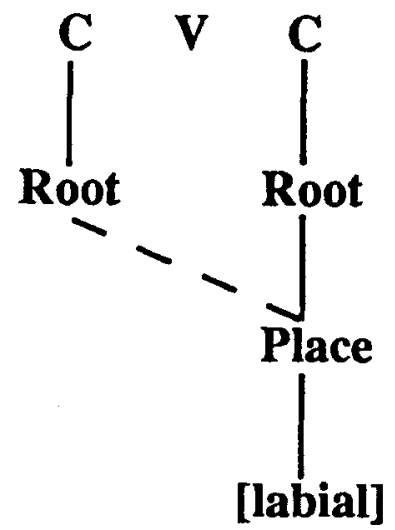

(c)

Figure 3. Account of place assimilation asymmetries: (a) ambient velars which are underspecified for place are targets of regressive place assimilation; (b) ambient coronals which are shadow-specified block as targets of assimilation; (c) those ambient coronals which are underspecified for place are targets of assimilation. 
sponded with ambient velars, and in the case of Subject L.P. they corresponded with coronals. In both cases, however, the correspondence was not across-the-board. It does not appear to be possible to predict a priori which of two classes will be shadow-specified. However, through interacting error patterns of the sort considered here, it was possible to determine on empirical grounds precisely which (if any) segments were shadow-specified. The fact that shadow-specified segments in L.P.'s system corresponded with ambient coronals had the effect of allowing ambient velars to be underspecified and thus targets of assimilation. In this case, then, the product of the fronting error pattern was able to be the target of the other error pattern. Importantly, however, in this case (and the other case), place assimilation still had to be blocked from applying to certain other segments. The end-result in the two case studies was that, at least with respect to place assimilation, the product of the fronting error pattern acted differently from the ambient coronals with which they were merged.

\section{Case study 3}

The particular interaction of the fronting and place assimilation error patterns observed in the above two case studies required an underlying distinction between ambient coronals and velars, although the substance of that distinction was different from that of the ambient system. That interaction exemplified only one of the two logically possible ways in which these error patterns might have interacted. The other logical possibility is for the product of fronting to act phonologically the same as the coronals with which they are merged. In other words, in cases where velars are excluded and replaced by coronals, can place assimilation apply equally to coronals that correspond to both coronals and velars? If place assimilation can apply to both in some children's systems, then it would suggest that ambient coronals and velars are represented the same underlyingly by those children, i.e. as underspecified.

Donahue (1986) reported the case of a normally developing child, Sean, who at age 1;3-1;6 can be seen from the forms in (7) to have exhibited a crucial interaction between the fronting and place assimilation error patterns. The forms in (7a) show that Sean excluded velars from the phonetic inventory, replacing them with coronals. Additionally, at that same point in time, the child evidenced a process of longdistance place assimilation (progressive and regressive). This error pattern replaced coronals (including those that corresponded with ambient velars) with a labial when a labial occurred elsewhere in the word. The data in $(7 \mathrm{~b})$ and $(7 \mathrm{c})$ illustrate the lack of a differentiation between ambient coronals and velars with respect to place assimilation.

(7) Sean, age 1;3-1;6 (Donahue, 1986)

(a) Ambient velars replaced by coronals

[titi] 'cookie' [d $\Lambda \mathrm{t}]$ 'duck'

[dodi] 'dog' [titat] 'tick-tock'

[titi] 'Katie' [dot] 'coat'

(b) Ambient coronals targeted for place assimilation

[pap] 'top' [bami] 'Tommy'

[pop] 'soap' [mipol] 'nipple' 


\section{[babal] 'bottle' [pum] 'spoon'}

(c) Ambient velars targeted for place assimilation

[bıp] 'cup' [bup] 'book'

[brp] 'big' [bıpəp] 'bucket'

An underspecification account of these facts would employ the same place assimilation rule required for the other cases considered here. The only difference would be in the nature of this child's underlying representations. More specifically, the fact that Sean's ambient coronals and velars acted the same, both serving as targets of assimilation, suggests that both were underspecified for place. The [labial] feature was then free to spread to both. In those words with no labial consonant (7a), the fronting error pattern would derive from a lack of a place distinction at the underlying level of representation with the feature [coronal] filled in by default. Sean's phonology thus differed from the other two only by having one fewer place distinction and thus one fewer specified place feature available to block assimilation.

Something similar to this account was hypothesized at an earlier stage of development for Subjects 18 and L.P. Recall in those cases that a few forms (especially (1e) and (5c), respectively) might have been expected to block as targets of assimilation, but did in fact undergo the rule. This lack of differentiation between two different ambient sounds suggested that the place contrast had not yet extended to those words, and that the children's underlying representations evolved by becoming more specified over time. If this is correct we might have expected Sean at a subsequent phase of development to have introduced a place contrast of some sort (either through shadow-specification or specification of [dorsal]) that would cause some segments to block as targets of assimilation. Precisely this occurred. Donahue noted (1986: 214) that velars came into the system between the ages 1;6 and 1;10. Those velars blocked as targets of assimilation, while coronals continued to undergo the rule. The introduction of velars did not, however, occur across-the-board. Some ambient velars continued to be produced as coronals and/or served as targets of assimilation. This suggests that those words remained underspecified for place. The velars that did appear also served as a trigger of assimilation, further suggesting that those items incorporated a specification for place at that stage. This subsequent phase of development was typical of what has been documented for many other normally developing and phonologically disordered children (e.g. Chin, 1993; Cruttenden, 1978; Ferguson et al., 1973; Menn, 1971; Smith, 1973). Quite possibly all the cited cases (including our Subjects 18 and L.P.) evolved from a system such as Sean's early phase where there was no underlying distinction between coronals and velars with place thus being underspecified for these segments. The next stage would then have introduced a place contrast, although not necessarily the ambient place contrast and not necessarily in all words. The data presented for Subjects 18 and L.P. reflected this development with the introduction of shadow-specification. Such a stage is one possible (but not necessary) intermediate step towards the acquisition of the ambient place contrast. For example, while Sean showed no evidence of an intervening stage involving shadow-specification, his acquisition of velars was similar to that of Subject 18 , who at a subsequent point in time added only a few velars with a corresponding reduction of the two error patterns. ${ }^{5}$

${ }^{5}$ These data were collected 12 months after the initial analysis immediately following treatment on three sounds, including the targets of assimilation. Comparable longitudinal data for Subject L.P. were not available due to subject attrition. 
Sean's early stage of development thus exemplified one of the other logically possible interactions of these two error patterns. In this particular interaction the product of one error pattern (fronting) was phonologically and phonetically indistinguishable from the segments with which it was merged, and was the target of another error pattern (place assimilation). The other interactions exemplified by Subjects 18

and L.P. also involved a phonetic merger, but in those cases the product of the error pattern acted differently, motivating an underlying distinction between underspecified and shadow-specified segments.

\section{Conclusion}

The various potential interactions of the two error patterns, fronting and place assimilation, were all shown to occur in the course of acquisition. A unified account of the interactions was unavailable when these children's underlying representations were assumed to be entirely ambient-like and static over time. On the other hand, when children's underlying representations were considered to evolve over time, departing from those of the ambient system by being underspecified or shadowspecified, a unified account was available which employed a single invariant rule of long-distance place assimilation. The superficial differences among the interactions followed from differences in the degree and substance of specifications in underlying representations. The particular interactions involving blocking effects (Subjects 18 and L.P.) further supported shadow-specification as an extension of underspecification theory. While our focus was on production facts and representations motivated by such facts, appeal to shadow-specification offers a possible solution to a problem alluded to at the beginning of this paper, namely how to account for the fact that some children appear to perceive ambient contrasts that they themselves do not produce. The phonological distinction between underspecified and shadow-specified representations accords with a child's perceptual judgement that two ambient sounds are different, but that phonological distinction would not necessarily result in a phonetic difference. This result is achieved without having to posit segment-types that do not occur phonetically or a dual lexicon that separates perception from production.

While the phenomena considered here were accounted for within a conventional derivational theory, it is expected that many of the arguments and conclusions would hold as well for a constraint-based theory such as optimality theory (Prince and Smolensky, 1993). For example, each of the two error patterns might be achieved by ranking certain markedness constraints more highly than faithfulness constraints, as in Gnanadesikan (1995). Additionally, the particular error pattern of longdistance place assimilation would probably be attributed to a highly ranked constraint which aligns the Place node, as in Goad (1996). The observed individual differences and interactions of these two error patterns are, however, theoretically more challenging. Within this theoretical framework, individual differences must be attributed to differences in the ranking of constraints and/or to differences in the nature of the inputs (underlying representations). If children's inputs are assumed to be ambient-like and uniform across children, differences would have to be attributed to different constraint rankings. While this might initially seem plausible as a characterization of differences across children, it is unclear whether such an assumption would allow for a non-paradoxical ranking of constraints within an individual child's system. Recall, for example, the ordering paradox that obtained in the case 
of Subject 18 where a particular ambient sound in some words could undergo assimilation but the same ambient sound in other words could not. This differential behaviour of the same ambient sound leaves differences in input representations as the more likely source of variation in the interaction of these error patterns. At the very least, then, some of these children's inputs must be permitted to differ from those of the ambient system. It remains to be determined whether such a framework would also allow those inputs to differ by being underspecified and shadow-specified as outlined above. If, however, underlying representations were recognized to differ within and across children in this way, faithfulness constraints could remain highly ranked (as in fully developed systems) with the observed developmental changes being attributable to changes and differences in the input representations. See Inkelas (1994) for arguments for the necessity of underspecification within optimality theory and Dinnsen (1996) for arguments for underspecification theory as an account of other acquisition phenomena.

The error patterns considered here are just two of several others with similar potential interactions. Any non-assimilatory substitution could yield a product that is a potential target of an assimilatory rule. For example, then, an error pattern that replaced a fricative with a stop (stopping) or replaced a liquid with a glide (gliding) would merge an ambient manner contrast. The product of those mergers in turn would be a potential target of a rule that spread some specified manner feature. The issue then in the case of a stopping error pattern, for example, would be whether stops corresponding to fricatives acted the same as other stops with regard to a process of manner assimilation. Several such cases involving manner features have been identified with interactions and blocking effects similar to those observed in this paper (Dinnsen, 1995). The documentation of these and other cases further informs our understanding of the occurring range of variation and of the theoretical machinery needed to account for that variation.

Aside from their theoretical implications, these phenomena also offer some insight into the course of acquisition, which in turn may be useful clinically for assessment, treatment, and the projection of learning. As we have seen, the fronting and place assimilation error patterns can co-occur in normally developing and phonologically disordered systems. The different interactions of these error patterns are suggestive of at least two different stages of phonological development. Each stage makes a different claim about what a child knows and has yet to learn. An interaction such as that in the case of Sean, where place assimilation targeted all coronals (even those that were the product of fronting), would appear to represent an early stage of development. In such cases the child's production facts fail to distinguish ambient coronals from velars, rendering them both equally vulnerable to error by place assimilation. The occurrence of these same effects in a phonologically disordered system could indicate that the child is unaware (at least for purposes of production and possibly for perception as well) of an ambient place contrast among non-labial consonants. To bring the child's system into conformity with the ambient system it may be necessary to explicitly teach the distinction between coronals and velars, possibly by means of minimal pair treatment with a focus on both production and perception (Weiner, 1981). While Sean (a normally developing child) spontaneously acquired the ambient place distinction, it should be noted that the contrast was not acquired across-the-board. Some words continued to be produced in error. The fact that velars were introduced appropriately in only some words is further evidence that Sean's underlying representations were non-ambient-like prior to the change. Thus, 
if a phonologically disordered child of this type were taught the place distinction, we might expect that child to also show similar effects of lexical diffusion. Such cases may thus require additional treatment on specific lexical items.

An intermediate stage of development is suggested by those cases (such as Subjects 18 and L.P.) where the two error patterns interacted such that place assimilation targeted only some coronals. When the production facts show segments to behave differently in accord with an ambient distinction, it is fair to conclude that the child has internalized an underlying distinction of some kind. Even if the distinction were not internalized exactly as in the ambient system, the presence of a distinction would seem to represent an advance over some other stage of development that is missing the contrast. Also, this internalized distinction may be sufficient to account for a child's presumed ability to perceptually differentiate ambient coronals and velars. From a clinical perspective the assessment of an intermediate stage should be important because the learning task that confronts children at different stages should presumably be different. In this particular intermediate stage the child must learn to phonetically implement his/her existing phonological contrast in a way that conforms with the phonetic properties of the ambient system. In the other case (i.e. an earlier stage of development) the child must learn something more, that there is a contrast and that it is implemented in a particular way. The relative ease/ difficulty of these two learning tasks has not yet been determined. Some possible parallels may, however, be available from the learning patterns of other phonologically disordered children who exhibited somewhat different error patterns. Consider, for example, those cases of presumed phonemic mergers where fine-grained acoustic analyses have revealed subtle but systematic phonetic differences in accord with the ambient distinction (e.g. Forrest, Weismer, Hodge, Dinnsen and Elbert, 1990; Tyler, Edwards and Saxman, 1990). In these cases the children maintained an ambient distinction phonetically and phonemically, but in a non-ambient fashion. The results further showed that the appropriate ambient contrast was acquired either spontaneously or with minimal clinical treatment. Other children who showed no evidence of differentiation (acoustically and phonologically) evidenced greater difficulty in acquiring the appropriate implementation of the ambient contrast. In another series of studies (Dinnsen and Elbert, 1984; Gierut, 1985), learning was found to positively correlate with the nature of children's underlying representations. When treatment was focused on errors attributable to ambient-like underlying representations, relatively high levels of success were achieved in remediating those errors. In some instances these errors were eliminated without direct treatment. One unifying conclusion from these various studies is that a child's underlying knowledge of contrasts (as determined from production data) contributes to the elimination of errors. Subjects 18 and L.P. evidenced some knowledge of an underlying contrast as revealed through the interaction of their error patterns. That knowledge apparently did not extend to the level of phonetic implementation. ${ }^{6}$ Nevertheless, while such knowledge may not have conformed in substance with the ambient contrast,

\footnotetext{
${ }^{6}$ In the absence of acoustic measures, we cannot be certain that there was no phonetic difference between the coronals that corresponded with ambient coronals and velars. Even if acoustic analyses had been completed, a finding of no difference must be regarded with caution. Differences may have existed in other measures that were not considered. Whatever the ultimate phonetic facts, an underlying phonological distinction can be motivated based solely on the particular interaction of these two error patterns.
} 
it might still be expected that this partial knowledge would facilitate the elimination of such errors. Consequently, little or no treatment may be needed in such cases. Also, since the nature of the problem is different in this intermediate stage (i.e. a problem of phonetic implementation), some form of treatment focusing on production (rather than perception) may be more appropriate. While an experimental evaluation of these hypotheses awaits testing, having identified the empirical characteristics of these presumed stages allows such hypotheses to be entertained with some promise.

\section{Acknowledgements}

We are especially grateful to Judith Gierut for comments on an earlier draft of this paper, and for making available to us her database on phonological disorders, from which Subject L.P. was selected. This work was supported in part by grants from the National Institutes of Health DC00260, DC00076, DC01694, and DC00012.

\section{References}

Archangeli, D. (1988) Aspects of underspecification theory. Phonology, 5, 183-207.

Archangel, D. and Pulleyblank, D. (1994) Grounded Phonology (Cambridge, MA: MIT Press).

Barton, D. (1980) Phonemic perception in children. In G. Yeni-Komshian, J. F. Kavanagh and C. A. Ferguson (Eds), Child Phonology: Perception, Vol. 2 (New York: Academic Press).

CHIN, S. B. (1993) The organization and specification of features in functionally disordered phonologies. Unpublished doctoral dissertation, Indiana University.

Cruttenden, A. (1978) Assimilation in child language and elsewhere. Journal of Child Language, 5, 373-378.

DinNsen, D. A. (1993) Underspecification and phonological disorders. In M. Eid and G. Iverson (Eds), Principles and Prediction: The Analysis of Natural Language: Papers in Honor of Gerald Sanders (Philadelphia, PA: John Benjamins).

DINNSEN, D. A. (1995) The manner node reconsidered (Paper presented at the 20th Annual Boston University Conference on Language Development, Boston, Massachusetts).

DinNSEN, D. A. (1996) Context-sensitive underspecification and the acquisition of phonemic contrasts. Journal of Child Language, 23, 57-79.

DinNsEN, D. A. and CHIN, S. B. (1994) Independent and relational accounts of phonological disorders. In M. Yavas (Ed.), First and Second Language Phonology (San Diego, CA: Singular).

Dinnsen, D. A., Chin, S. B., Elbert, M. and Powell, T. W. (1990) Some constraints on functionally disordered phonologies: phonetic inventories and phonotactics. Journal of Speech and Hearing Research, 33, 28-37.

DinNSEN, D. A. and ElBERT, M. (1984) On the relationship between phonology and learning. In M. Elbert, D. A. Dinnsen and G. Weismer (Eds), Phonological Theory and the Misarticulating Child (ASHA Monographs No. 22) (Rockville, MD: ASHA).

DonaHue, M. (1986) Phonological constraints on the emergence of two-word utterances. Journal of Child Language, 13, 209-218.

Dyson, A. T. (1986) Development of velar consonants among normal two-year-olds. Journal of Speech and Hearing Research, 29, 493-498.

Ferguson, C. A., Peizer, D. B. and Weeks, T. E. (1973) Model-and-replica phonological grammar of a child's first words. Lingua, 31, 35-65.

Forrest, K., Weismer, G., Hodge, M., Dinnsen, D. A. and Elbert, M. (1990) Statistical analysis of word-initial $/ \mathrm{k} /$ and $/ \mathrm{t} / \mathrm{produced}$ by normal and phonologically disordered children. Clinical Linguistics and Phonetics, 4, 327-340.

GieruT, J. A. (1985) On the relationship between phonological knowledge and generalization 
learning in misarticulating children (PhD thesis, Indiana University, Bloomington, IN: Indiana University Linguistics Club).

GIERUT, J. A.. (1994) Cyclicity in the acquisition of phonemic distinctions. Lingua, 94, 1-23.

Gierut, J. A., Simmerman, C. L. and NeumanN, H. J. (1994) Phonemic structures of delayed phonological systems. Journal of Child Language, 21, 291-316.

GNANADESIKAN, A. (1995) Markedness and faithfulness constraints in child phonology (Unpublished manuscript, University of Massachusetts, Amherst). (Also available in the Rutgers Optimality Archive.)

GOAD, H. (1996) Consonant harmony in child language: evidence against coronal underspecification. In B. Bernhardt, D. Ingram and J. Gilbert (Eds), Proceedings of the University of British Columbia International Conference on Phonological Acquisition (Somerville, MA: Cascadilla Press).

IngRam, D. (1989) Phonological Disability in Children, 2nd edn (London: Cole and Whurr).

INKELAS, S. (1994) The consequences of optimization for underspecification. Proceedings of the Northeastern Linguistics Society, 25, 287-302.

KIPARSKY, P. (1976) Abstractness, opacity, and global rules. In A. Koutsoudas (Ed.), The Application and Ordering of Grammatical Rules (The Hague: Mouton).

KRONVALL, E. and DIEHL, C. (1954) The relationship of auditory discrimination to articulation defects of children with no known organic impairment. Journal of Speech and Hearing Disorders, 19, 335-338.

Menn, L. (1971) Phonotactic rules in beginning speech. Lingua, 26, 225-251.

MENN, L. (1976) Pattern, control, and contrast in beginning speech: a case study in the development of word form and word function (Unpublished PhD thesis, University of Illinois, Champaign.

NitTrouter, S. and StUdDERT-KENNEDY, M. (1987) The role of coarticulatory effects in the perception of fricatives by children and adults. Journal of Speech and Hearing Research, 30, 319-329.

Paradis, C. and Prunet, J. F. (Eds) (1991) Phonetics and Phonology, Vol. 2: The Special Status of Coronals: Internal and External Evidence (San Diego, CA: Academic Press).

PRINCE, A. and SMolensky, P. (1993) Optimality Theory: Constraint Interaction in Generative Grammar. Technical Report \#2 of the Rutgers Center for Cognitive Science (Rutgers University).

Smrth, N. V. (1973) The Acquisition of Phonology: A Case Study (Cambridge: Cambridge University Press).

SPENCER, A. (1986) Toward a theory of phonological development. Lingua, 68, 3-38.

Stoel-Gammon, C. and Stemberger, J. P. (1994) Consonant harmony and phonological underspecification in child speech. In M. Yavas (Ed.), First and Second Language Phonology (San Diego, CA: Singular).

Tyler, A. A., Edwards, M. L. and SaXman, J. H. (1990) Acoustic validation of phonological knowledge and its relationship to treatment. Journal of Speech and Hearing Disorders, 55, 251-261.

WEINER, F. F. (1981). Systematic sound preference as a characteristic of phonological disability. Journal of Speech and Hearing Disorders, 46, 281-286. 